\title{
Wage inequality, skills and mastering new technologies
}

\author{
Jose M. Quintero-Holguin * \\ Advisor: David Perez-Reyna ${ }^{\dagger}$
}

\begin{abstract}
In this paper I provide a new explanation for the raising inequality between skilled and unskilled. Unlike the skilled biased technological change explanation, I do not assume that new technologies are necessarily complementary with skills. Instead, the adoption of new technologies have mastering costs that have a inverse relation with skills. Thus, skilled individuals master new technologies faster than unskilled individuals which gives them edge apart from being more skilled. The model predicts changes in the distribution of wages in favor mainly of agents in the tails of the distribution. As a result, the gap between skilled and unskilled increases and the general levels of inequality of the economy also rises. Finally, the model highlights the importance of considering the costs of mastering new technologies.
\end{abstract}

Key Words: Skill-biased technological change, wage structure, adopting technologies, problem solving based model, skill premium.

JEL Codes: C60, D31, J31, O33

\footnotetext{
*Universidad de los Andes, email: jm.quintero925@uniandes.edu.co. University code: 201023390

†Universidad de los Andes, email: dav-pere@uniandes.edu.co.
} 


\section{Introduction}

The skilled biased technological change has become a popular explanation for the growing inequality between skilled individuals. There is a wide literature studying the channels through which highly skilled agents benefit from the introduction of new technologies more than unskilled agents such as Acemoglu (1998). And even though the skill-biased technological change studies concludes that skills and new technologies are complementary, Mokyr (1990) presents a series of examples through the eighteenth and nineteenth centuries in which new technologies were substitutes to skills, rather than complementary. Computers for example, can perform complex optimization problems that previously could only be done by highly skilled individuals. Equally important, there is an existing literature exploring the relation between skill obsolescence and technological change such as Allen \& de Grip (2012). In this paper I provide a new explanation for the raising inequality between skilled and unskilled. Unlike, the skilled biased technological change explanation, I do not assume that new technologies are necessarily complementary with skills. Instead, the adoption of new technologies have mastering costs that have a inverse relation with skills. Thus, skilled in-

dividuals master new technologies faster than unskilled individuals which gives them edge apart from being more skilled.

Despite the ambiguity in the relationship of skills and technology, empirical evidence shows a positive relation between technological progress and wages of skilled individuals. Autor et al. (1998) studies the role of the skill-biased technological change on the structure of wages in the U.S, thus showing how the skill-biased technological change has increased the relative demand for skills in the U.S labor market. Later Beaudry et al. (2006) shows that places with a higher supply of skills, adopted new technologies more aggressively and therefore the effects of skill-biased technological change were more intense. Moreover, Weiss (2008) claims that even though the skill-biased technologically will increase at first inequality between skilled and unskilled, technical change will also transform preferences and therefore changing output prices in favor of the unskilled. On the contrary, the model I present does not assume a complementary relation between skills and technology. The model explains the reason behind the rapid adoption of technologies described in Beaudry et al. (2006). Nevertheless, since the model is not assuming that skills and technology are complementary, it is consistent with historical examples of technology while still being able to describe a positive relation between technological change and wages of skilled individuals. 
One feature that all this literature has fail to address though, is the cost of learning new technologies. As pointed out in Jovanovic \& Nyarko (1996) the adoption of new technologies is a hard activity because of the high costs of learning. ${ }^{1}$ This fact raises an important question about the nature of technology: Is technological progress really skill-biased or alternatively high skill agents benefit more from technology because the cost for them to adopt new technologies is lower? This work introduces a problem solving based model in which agents invest in different inputs to solve problems and sell their solutions in the market. The model has heterogeneous agents endowed with a skill coming from a continuous distribution. As noted in Acemoglu \& Autor (2011) the canonical model that analyzes changes in skill premium consider two clusters of agents: skilled and unskilled. Though this was a good starting point, it has become insufficient to analyze some trends in the wages of the skilled and unskilled. Galor \& Moav (2000) conclude that wage inequality has increased not only between skilled and unskilled but also within these groups. Therefore the necessity of introducing a continuum of skills. Moreover, the skill plays two major roles in the decisions agents face. First the skill level is one of the variables that sets the problem-constrain for each individual. Higher skill levels allows individuals to solve harder problems. The skill will also play a role in how easy an agent adopts new technologies. This feature of the model is consistent with remarks made by Nelson \& Phelps (1966).

Moreover, Acemoglu \& Autor (2011) highlight that the canonical model does not distinguish between skills and occupations so the skilled. Similar to Acemoglu \& Restrepo (2016) wages are determined by the difficulty of the problem agents solve. However, there is not creative destruction. Problems that have been solved will always exist but their relative value will decrease because of technological progress. Caicedo et al. (2016) shows that high paying problems have become harder giving highly skilled individuals a comparative advantage in the market and therefore polarizing the distribution of wages. This model keeps the feature that highly skilled workers have a comparative advantage in problem solving as the skill level affects the problem solving boundary. However, it claims that there is another source of wage inequality. Highly skilled workers can adopt new technology faster and consequently augment their comparative advantage in the market as in Beaudry et al. (2006). This feature can explain the increase of inequality within groups of skilled and unskilled mention in Galor \&

\footnotetext{
${ }^{1}$ Jovanovic \& Nyarko (1996) shows that mastering a technology can prevent agents to later on switch to a more productive technology because of the cost of learning and mastering a new technology.
} 
Moav (2000) since access to technology also explains differences in wages even for individuals with the same skill level. Moreover, skilled agents that fail to adopt new technologies properly may be displaced to solve problems often solved by unskilled individuals. This claim is consistent with the findings of Beaudry et al. (2009) where they assert that poor employment outcomes during the 2000's had to do with skilled individuals displacing unskilled from their jobs.

Granted that skills also play a role in the adoption of new technologies, the model incorporates these costs of mastering when agents invest in new technologies. Investing in new technologies has a fixed price but agents get discounts depending on their skill. Highly skilled agents get bigger discounts because their mastering costs are smaller. Given a benchmark calibration I analyze how the decision of investment is affected when I change the parameters related to this decision. I find that the decision is robust when I change the parameters that determine the price of investment such as the fixed initial price or the range of discount. When I change the importance of technology for solving problems, the results are magnified though the analysis remains the same. Intuitively, parameters affecting the price of investment does not have a direct effect on the structure of wages. In contrast, changing the importance of skills when solving problems implies an structural change in the structure of wages due to the fact that skills are time invariant and a group of agents will have a permanent advantage. Additionally, I show how the relation between skills and investment is consistent with the empirical data on a macroeconomic level. Specifically, the model is able to predict changes in the distribution of wages consistent with findings done by Alichi et al. (2016). Also, the model fits qualitative the empirical relation between skills and expenditure in R\&D. Finally, costs of mastering new technologies become a new channel that explains the increasing wage inequality between skilled and unskilled individuals. Without these costs, skilled and unskilled could access similar levels of technology and thus removing one source of inequality. In the light of these findings, the model is able to provide new explanation for the rising inequality between skilled and unskilled. Furthermore, the explanation provided is consistent with the data and examples in history where new technology can be categorize as substitutes of skills.

The rest of this work has the following structure. Section II studies some macroeconomic trends related to technological progress, demand of skills and others. Assuming that the rate of introduction of new technologies has a positive relation with R\&D expenditure, I show how 
investing in $R \& D$ affects the average agent rather that the low skilled agent. Next, in section III presents a model that encloses the theoretical frame through which I try to describe the different dynamics of investing in $\mathrm{R} \& \mathrm{D}$ when there are heterogeneous agents in the economy. Subsequently, section IV does a quantitative analysis from the results of the model. First a do comparative statics to understand the effect of certain parameters in the model. Then I test some of the model predictions against the data and existing literature. Finally, section V present conclusions.

\section{Empirical Evidence}

Before describing the model I present some empirical evidence that motivate the mechanisms I will later describe. Specifically, in this section I provide suggestive evidence of how the introduction of new technologies will increase the demand of people with high education. Moreover, how the introduction of new technologies will make middle educated individuals less appealing to the market relative low educated individuals. This motivates changes in the middle of the distribution of wages mention previously. To do so, this work relays on three main data sources. First, using the OECD open database I am able to identify evidence regarding the labor demand of skilled individuals. Next, I merge the World Intellectual Property Organization (WIPO) open database with the World Bank open database to show the importance of research and development on income. The section manage to present some suggestive correlations between the introduction of new technologies and demand for skilled individuals relative to unskilled. The main findings, is that while there is a positive correlation between introduction of new technologies and the employment rate of highly educated individuals relative to individuals with middle education, the correlation becomes negative when the the relative employment rate is middle educated individual over low educated individuals.

\section{II.1 Labor market trends}

Thus, a good starting point is to analyze how having more technology benefits skilled agents. Granted that skilled agents adapt easily to new technologies, then the demand for skills must be higher when the economy has more access to technology. Though the demand for skills is not observed, the employment of highly educated individuals can be used as a proxy.

To do such analysis I use the panel data from the OECD open database together with the 


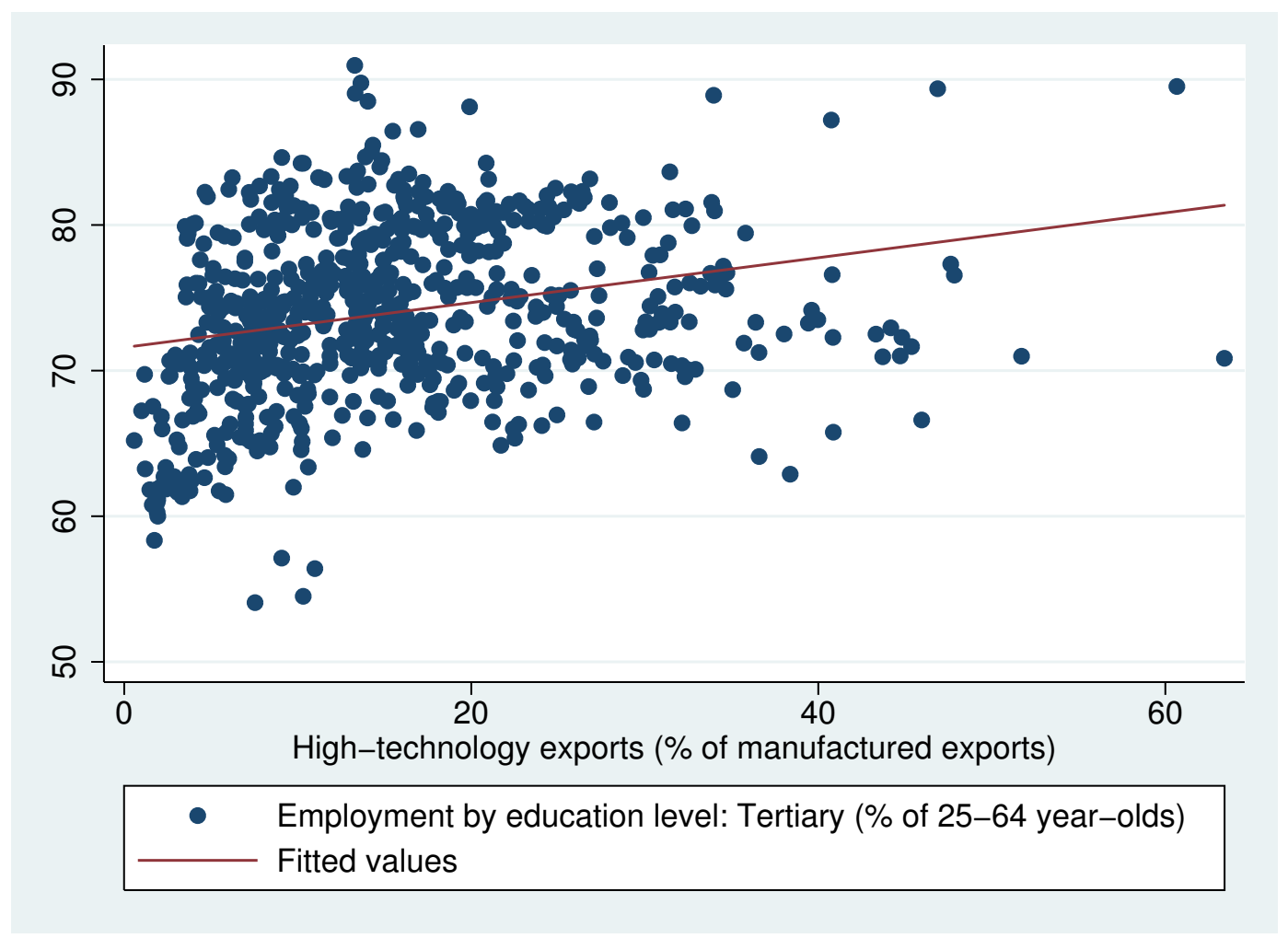

Figure 1: Demand of skills and technology

World Bank database. The result is a panel from 1981 to 2015 with 43 different countries members of the OECD. Since the sample only considers countries from the OECD, all the analysis done will be biased towards medium or high income countries. I assume that higher levels of high-tech exports as a percentage of manufactured exports implies that in general terms the economy has more technology. If skilled people does benefit from new technologies, these countries should have a higher demand for skills and thus higher employment rates for people with tertiary education. Figure 1 shows a positive relation between these two variables. One way to interpret that positive relation is that the market finds more appealing individuals with tertiary education when there is more available technology. I use High-tech exports instead of government expenditure on $R \& D$, or any other variable affected by GDP growth, to avoid a spurious relation. Government expenditure on R\&D rises as GDP grows. Using variables of such nature can lead to an endogenous relation considering that employment rate also increases with GDP growth. In contrast, in spite of the fact that GDP can have an effect on exports, it is not direct that higher levels of GDP have an effect on the composition of exports. 


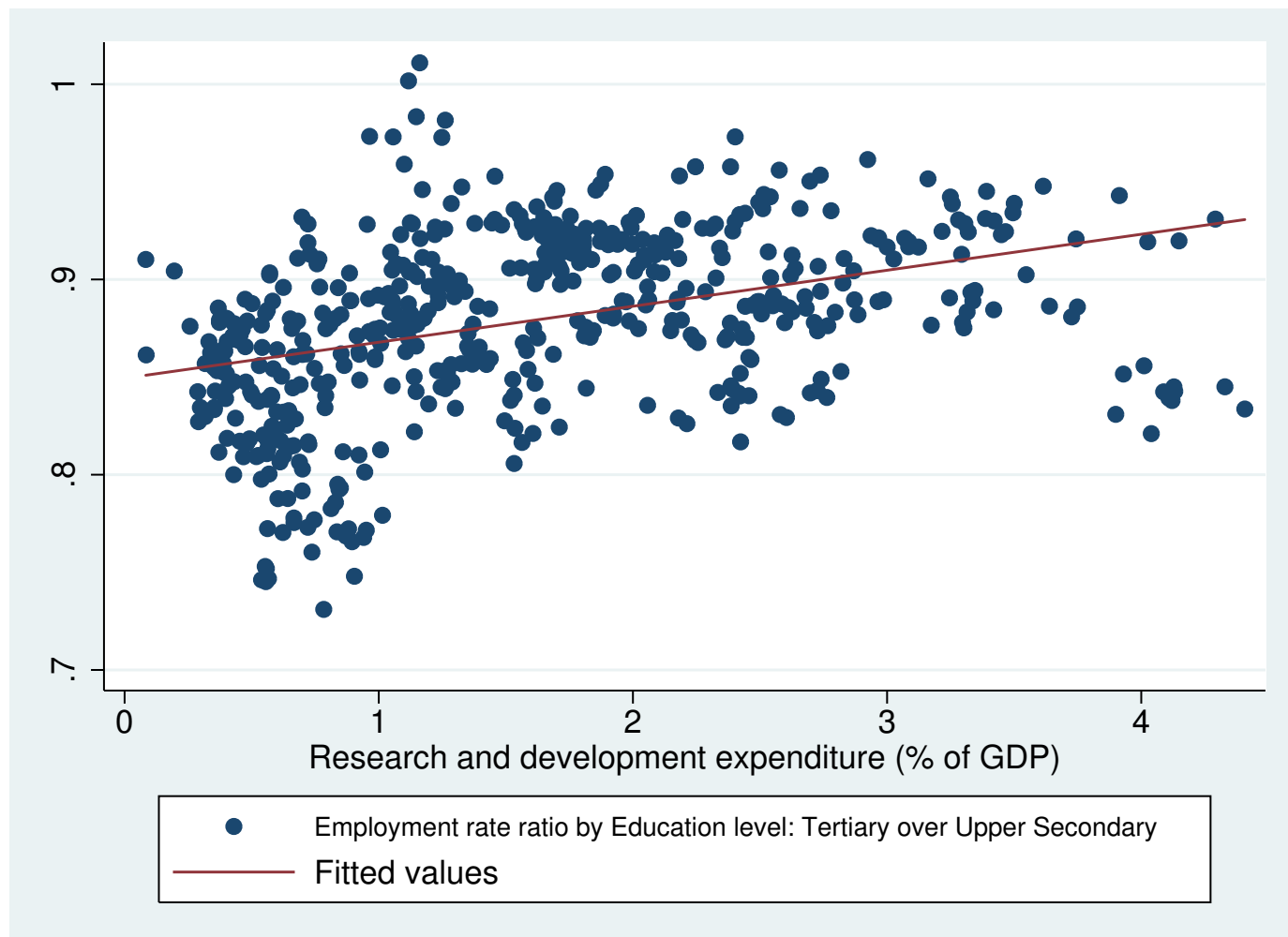

Figure 2: Expenditure in R\&D and relative employment rates

\section{II.2 Wage polarization}

In spite of suggesting that skilled individuals benefit from having a more technological economy, Figure 1 does not do any assertion on the effects technology has on the unskilled. To compare the effect of technology on different groups of skills I use the ratio of employment between those groups. Figure 2 studies the relation between the quotient between employment rate for people with tertiary education and employment rate for people with upper secondary education with government expenditure. Since I an comparing relative employment rates, then any shock to the economy that has an effect on both rates and on government expenditure in $R \& D$ is cleaned from the relation. Figure 2 suggests that when the expenditure in $R \& D$ is higher, individuals with tertiary education become more attractive than individuals with upper secondary. Assuming that on average more educated people have higher level of skills, figure 2 indicates that high skilled individuals benefit more from government expenditure on R\&D.

This however does not mention the less skilled individuals in the economy. Caicedo et al. 


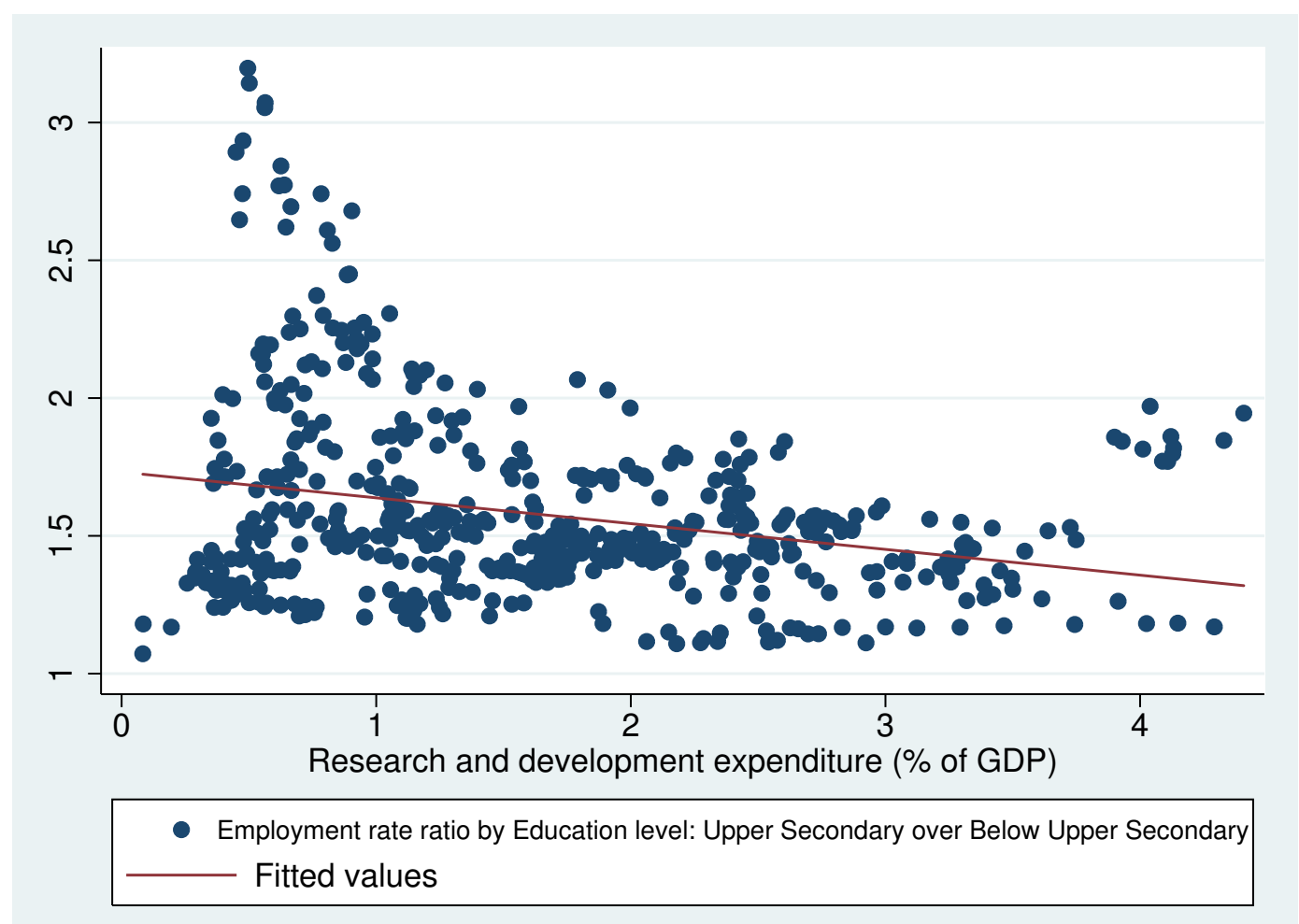

Figure 3: Expenditure in R\&D and relative employment rates

(2016) remarked that as problems become more complex to solve, skilled individuals benefit more from the increasing difficulty and consequently magnifies the wage gap. Additionally, Acemoglu \& Autor (2011) highlights that technology mainly has an effect on middle skilled individuals. Thus, introducing technologies often does not have an effect on low income tasks such as services. Figure 3 shows a negative relation between the ratio of employment rates and R\&D expenditure. This suggests that higher levels of expenditure in R\&D makes less appealing individuals with upper secondary relative people with no upper secondary. Assuming once again that more education on average implies higher levels of skills, figure 3 suggests that investing in R\&D has a stronger effect on the middle skilled individuals rather tan on the low skilled. 


\section{The model}

The model presented in this work is a problem solving based similar to the task-based model presented by Acemoglu \& Restrepo (2016). Furthermore, in Acemoglu \& Restrepo (2016) some of the tasks are destroyed since they are no longer needed in the production process. In this context, problems always exist but as they tend to get simpler their economic value will drop and agents will stop solving them. Moreover, as remarked previously, agents with different levels of skills face different costs when acquiring new technologies. This feature will be incorporated into the household decision as the price for investment skill dependent. This section is divided into three different subsections. First I present the context in which agents solve problems and what are their restrictions for it. Next I introduce the firm sector and find the price for problems for each agent. Finally I introduce the household problems and discuss each of the restriction they are facing.

\section{III.1 Solving problems}

Consider an economy with a set of agents $N$. Each agent is endowed with a skill $s$ which is a realization from a known continuous probability distribution with cumulative distribution function $F(s)$ and density $f(s)$. s should be interpreted as a measure of cognitive skills from individuals. Additionally, each agent has access to research capital $\kappa \in[0,1]$. Low levels of $\kappa$ represents obsolete research capital. while higher levels of $\kappa$ implies that the individual has access to sophisticated machines or theoretical methods which will allow him to solve harder problems. Assume there is a constant flow of new technologies that make research capital obsolete at a constant rate of $\delta$. Thus, agents must invest in research capital to have access to the newest technologies available in the economy. These are the two primordial inputs agents require to solve problems. Together they define each agent research potential as in equation 1

$$
h(s, t)=\left(\omega \kappa(t)^{\rho}+(1-\omega) s^{\rho}\right)^{\frac{1}{\rho}} .
$$

The research potential defines the set of problems an agent can solve by combining both the skill and capital access an agent has. To get a better understanding, consider two researchers identical in terms of skills and education, but located in different research centers. The researcher who is located in the best endowed center, in terms of technology or peers, will most likely be able to solve harder problems even though they are indistinguishable in terms of 
skills.

Next, define problems in the economy. A problem in this economy is represented by a number $x \in \mathbb{R}_{+}$which represents the difficulty of the problem. Each agent faces a constrain on the set of problems he can solve. The set of feasible problems for an agent is defined as

$$
P(s, t) \equiv\left\{x \in \mathbb{R}_{+} \mid x \leq h(s, t)\right\}
$$

Assume agents only have one unit of labor per period and solving one problem consumes one unit of labor, regardless of its difficulty. This restriction forbids agents to solve more than one problem per period and it will come as a key point in section III. 2 since it sets a bound to the numbers of problems each agent can sell to the firm. In other words, if $q$ denotes the number of solutions each agent develops per period, $q \leq 1$.

The set in 2 shows the two possible channels for solving hard problems. Skilled people have comparative advantage relative to the unskilled when the capital factor is constant. However, unskilled agents may compensate this by investing in capital. Later in section III.3 I present in detail each agent optimization problem. Nevertheless, this highlights one key characteristic of the model. Though skills play a major role in an agent ability to solve problems, access to capital will also be determinant and hence initial endowments will play an important role in the economy. Moreover, notice that the role of $\omega$ will be key to the analysis since it can be interpret as a degree of the advantage skilled individuals will have and how important having capital will be in the economy.

\section{III.2 Firms}

Next I describe the problem of the firms. Assume there is one big firm that produces a final consumption good. The firm buys solutions to problems from the agents and transform them into the final good. Assume each agent comes up with a unique solution, each solution with different applications. In this scenario, agents sell their problems to the firm under monopolistic competition. To aggregate the solution of problems the firm uses a CES technology, and the total production of the final good is given by equation 3

$$
Y(t)=\left(\int_{N}(q(i) x(i))^{\sigma} \mathrm{d} i\right)^{1 / \sigma}
$$

where $q(i)$ is the quantity of problems the firm buys to the agent $i, x(i)$ is the degree of difficulty of the problem solved by the agent $i$ and $0<\sigma<1$. I take the consumption good 
as the numeraire. Given equation 3, the firm maximization problem is described in equation 4

$$
\max _{\{q(i)\}}\left(\int_{N}(q(i) x(i))^{\sigma} \mathrm{d} i\right)^{1 / \sigma}-\int_{N} q(i) w(i) \mathrm{d} i
$$

where $w(i)$ is the wage the agent $i$ receives for solving problems. The first order condition for 4 yields the wage function for each agent. Equation 5 shows that under optimal behavior wages are determined by the number of problems each agent solves and their difficulty.

$$
w(i)=\left(\int_{N}(q(j) x(j))^{\sigma} \mathrm{d} j\right)^{\frac{1-\sigma}{\sigma}} q(i)^{\sigma-1} x(i)^{\sigma}
$$

Recall that each agent can only solve on problem in each period. Therefore agents supply inelastically one problem each period or $q(i)=1$ for every $i$. This yields the market clearing condition for each individual market and therefore in equilibrium, the price for each agent problem

$$
w(i)=\left(\int_{N} x(j)^{\sigma} \mathrm{d} j\right)^{\frac{1-\sigma}{\sigma}} x(i)^{\sigma}
$$

However, agents can choose the difficulty of their problems which affects their wage as in equation 6 . If $x(i)>0$ then

$$
\frac{\partial w(i)}{\partial x(i)}>0
$$

This will come as a key point later on, because even though agents cannot increase their wage by solving more than one problem, they can use their full potential to solve the hardest possible problem and increase therefore increase their wage. Furthermore, integrating equation 6 yields the equilibrium output of the economy

$$
Y^{\star}=\left(\int_{N} x(i)^{\sigma} \mathrm{d} i\right)^{1 / \sigma} .
$$

This allows us to rewrite equation 6 as

$$
w(i)=Y^{\star}\left(\frac{x(i)}{Y^{\star}}\right)^{\sigma}
$$

which can be interpreted as the wage of each agent is the total production of the economy, multiplied by each agent contribution to production. This makes equation 7 more intuitive, in the sense that solving harder problems contributes more to output production and thus, wages should be higher. 


\section{III.3 Optimization problem}

Now I describe household maximization. So far, I have only mention one decision from each household: the difficulty of the problem it solves. Assume all agents have the same utility function $u(c(t))$ satisfying first derivative positive and second derivative negative. Aside from deciding the difficulty of the problem they will solve, agents must choose their level of consumption and their investment for next period. The problem is describe in 9:

$$
\max _{\{\kappa(t+1), c(t), x(t)\}} \sum_{t=0}^{\infty} \beta^{t} u(c(t))
$$

subject to

$$
\begin{aligned}
w(t) & =c(t)+p(s) I(t), \\
\kappa(t+1) & =(1-\delta) \kappa(t)+I(t), \\
w(i) & =Y^{\star}\left(\frac{x(t)}{Y^{\star}}\right)^{\sigma} \\
I(t) & \geq 0, \quad x(t) \in P(s, t) \\
\kappa(0), s & \text { given. }
\end{aligned}
$$

where $p(s)=\bar{p} \frac{(b-F(s))}{b}$ and $F$ is the cdf of skills distribution. Equation 10a holds the biggest assumption so far. The second term to the right hand side of the equation states that price for investment depends on the skill of individuals. Recall that $\kappa$ should be interpreted as a qualitative variable rather than a quantitative. Therefore, price of investment should not be interpret a merely market price but also it contains learning and mastering costs. I assume that high quality capital has a higher mastering costs. If high levels of skills reduce learning costs, it is a reasonable assumption that each agent faces a different price when investing in capital. In this context, $\bar{p}$ represents a benchmark price for improving capital quality, $\delta$ should not be read as a depreciation rate but more like an obsolescence rate. $b \in \mathbb{N}^{\star}$ is a parameter that capture how much skill matters for mastering new capital. When $b$ is low, skilled agents get larger discounts. However, when $b \rightarrow \infty$ the limit price is $\bar{p}$ regardless of the skill level.

In the light of expression 7, agents have incentives to solve the harder problem in their feasible set. Also, notice that agents are indifferent on the difficulty of the problem they solve since harder problems have no extra cost. Consequently, agents will solve the harder problem on their feasible set which is $h(s, t)$. Before describing the equilibrium of the economy, 
consider problem 9 in recursive form. Let $V(\cdot)$ be the value function from each agent. Then the Bellman equation for problem 9 is

$$
V(k, s)=\max _{\substack{k^{\prime} \\ x \in P(s)}} u\left(Y^{\star}\left(\frac{x}{Y^{\star}}\right)^{\sigma}-p(s)\left[k^{\prime}-(1-\delta) k\right]\right)+\beta V\left(k^{\prime}, s\right)
$$

The Bellman equation in 11 yields an optimal policy function $g$ for next period capital. Given $g$, a recursive competitive equilibrium in this economy is a set of functions $(g, V, p, w)$ such that $V$ satisfies equation 11, $f$ is the associated optimal policy function, $g(k, s)=k+I, p(s)$ is the price for investment depending on $s$ and $w(s, k)$ is the wage to which each firm buys problem to agents such that each individual market clears.

\section{Quantitative Analysis}

\section{IV.1 Comparative Statistics}

Prior to test the model against the data I calibrate and do comparative statistics to understand how sensitive are agents to parameters that have an effect on investment. Several parameters are chosen to match some macroeconomics trends. This will be further explored in the next section.

Table 1: Benchmark parameters

\begin{tabular}{lcc}
\hline \hline Description & Symbol & Value \\
\hline Capital Share in Human Capital & $\omega$ & 0.5 \\
Elasticity between skills and technology & $1 / 1-\rho$ & 1.01 \\
Elasticity between wages and problems & $\sigma$ & 0.85 \\
Obsolescence rate & $\delta$ & 0.4 \\
Price of capital & $\bar{p}$ & 7.5 \\
Discount parameter & $b$ & 4 \\
Utility function & $u(\cdot)$ & $\ln (\cdot)$ \\
\hline \hline
\end{tabular}

I begin by presenting the policy function for capital $g$. To do so I set a baseline calibration which is described in table 1 . Then I change one parameter at the time while keeping the rest of the calibration fixed. As described in equation 11 each agent policy function depends on both his current level of capital and his skill level. Instead of presenting one policy function 
for each skill level, I present the expected policy function in figure 4. The black line in figure

Figure 4: Bench Mark policy function

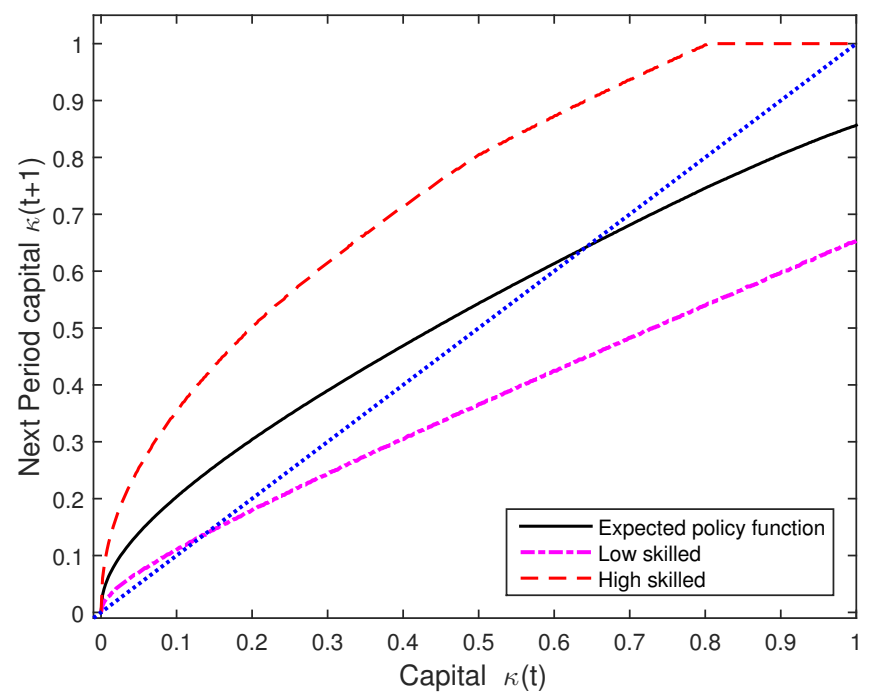

4 represents expected capital over the skill distribution or $\mathbb{E}_{s}(\kappa(t+1))=\mathbb{E}_{s}(g(\kappa(t), s))$. The red dashed lines are bounds representing the policy functions given that the agent has the highest skill level in the economy and the lowest skill level. One interesting trait about figure 4 is that the average policy function is closer to low-skilled policy function. This suggests that skills have diminishing costs on acquiring new capital. Table 1 is done such that

Figure 5: Comparative statics for $\omega$. Policy function.
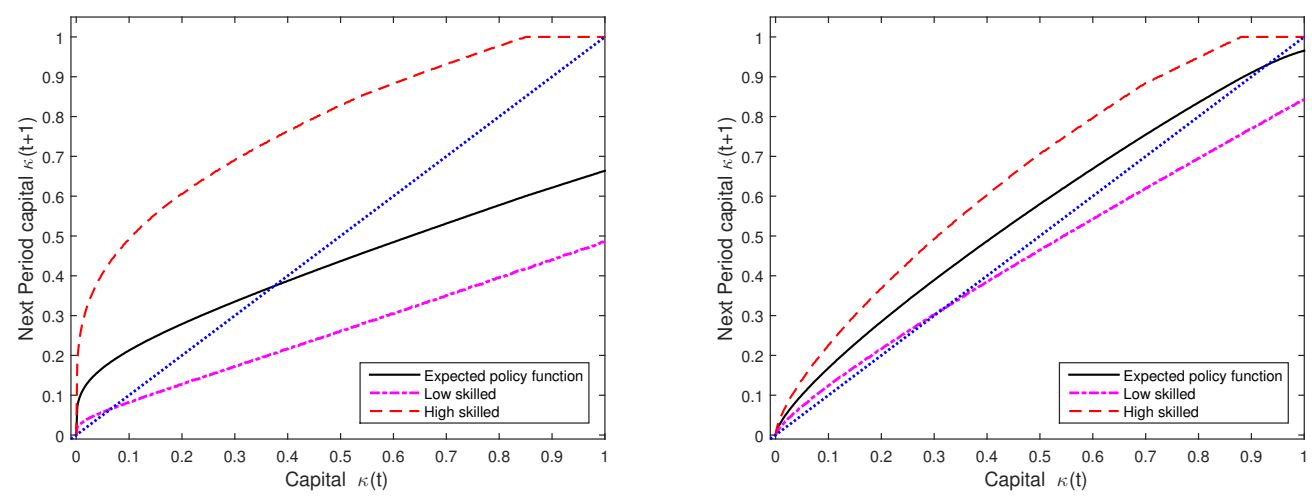

for this benchmark economy, skills and capital are equally important for solving problems. Therefore, low skilled agents can compensate by acquiring high quality capital and solving 
harder problems. Figure 5 presents the policy function for two different values of $\omega$. Panel to the left plots the policy function when $\omega=0.75$ and panel to the right plots the function when $\omega=0.25$. in the first case, when the ability to solve problems is highly dependent of capital, low skilled agents are able to compensate their disadvantage through the acquisition of capital. Consequently, the policy function is not far off from the skilled agents even though they face higher prices. However, observe that low skilled agents never reach the top quality capital. This implies that the function has a fixed point strictly lower than one and therefore their capital level in stationary state will be lower than one. This differences in capital lead to differences in the ability to solve problems and consequently increase polarization of wages. In contrast, the right hand side of figure 5 shows a different scenario in which skills are fundamental for solving problems and a key determinant of wages. In this case, the difference between low skilled and high skilled agents drastically increase. Like in figure 4, the average policy function is closer to the low skilled policy than to the high skilled policy. Furthermore such differences imply that wage inequality has two different sources in this scenario. First, skilled agents are able to solve harder problems and this will have a positive direct impact on their wage. Then, skilled agents also have advantage when accumulating capital which will also give them an edge in their ability to solve problems.

Figure 6: Comparative statics for $\bar{p}$. Policy function.
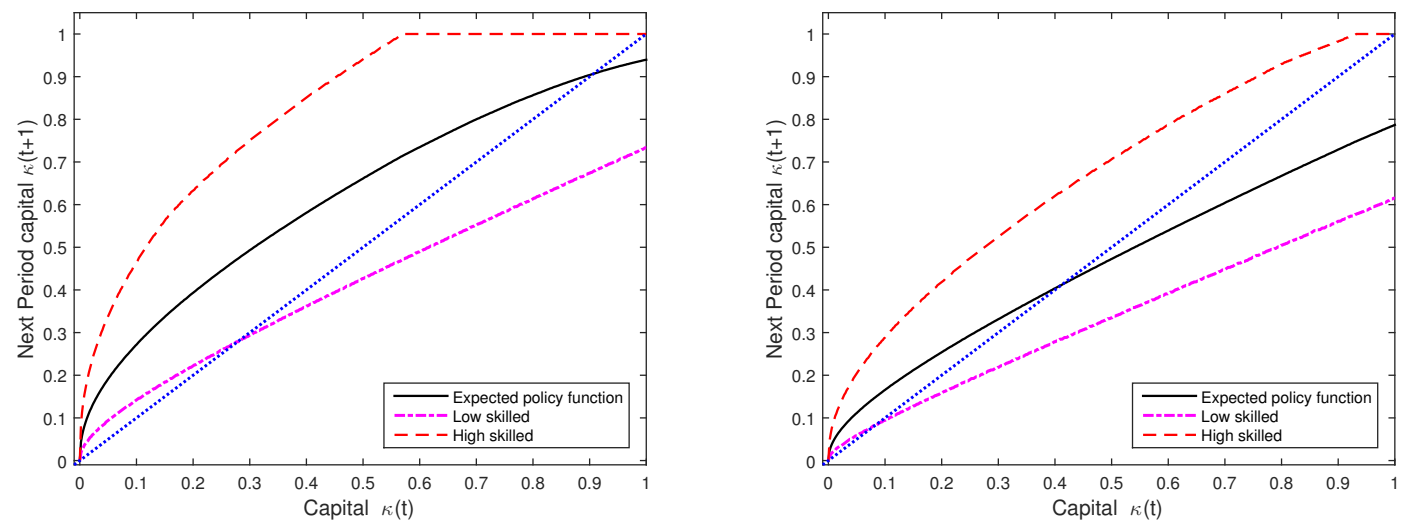

Though changing the value of $\omega$ has an effect on how agents invest in capital, it is explaining increases in wage inequality in a very similar way as the skilled biased technological change explanation. In summary, $\omega$ is dilating the feasible set of problems agents can solve. In contrast, changing $\bar{p}$ and $b$ has an effect on the capacity of investment while keep- 
ing the set of feasible problems fixed. Figure 6 presents the policy function when the base price for investing in technology $\bar{p}$ is change. Recall that agents have to pay $\bar{p}$ for every unit of technology and skilled agents can get up until $1 / b$ discount. This means that under the baseline calibration, agents can get up until $25 \%$ of discount depending on how skilled they are. However, if the baseline price is change, more or less agents will have enough resources for acquiring technology despite the skill discount. Panel to the right in figure 6 reduces the baseline price by one third and to the right increases the price by one third. When the price is reduce, skilled agents quickly converge to the highest quality capital in the economy and on average agents do get best quality capital in the economy. Contrary, when the baseline price increases, the average agent will not reach the best quality capital. In fact, the average policy function has a fixed point near 0.5 which implies that the average agent will have mid quality capital on stationary state. Moreover, though the proportional discount remains constant, in absolute term the discount becomes higher and therefore skilled agents take advantage from it.

Figure 7: Comparative statics for $b$. Policy function.
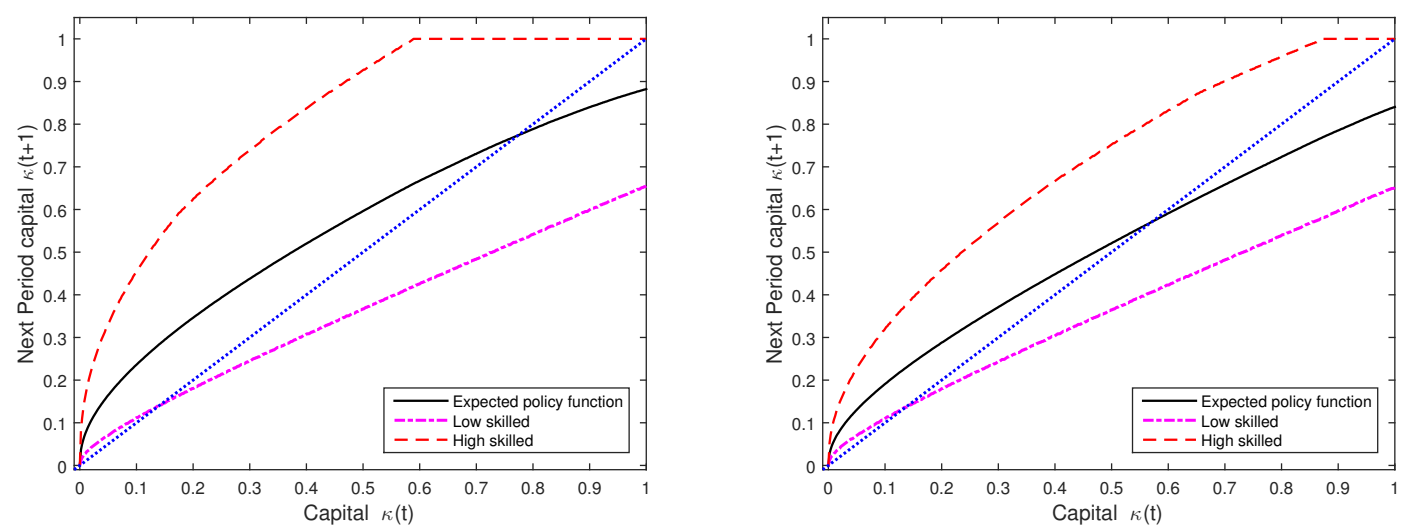

Finally, I analyze the effect of changing the discount agents receive. Recall that the discount is a nonlinear function that ranges from 0 to $1 / b$. Under the baseline calibration presented in table 1 the discount can go up until 25\%. Figure 7 presents the policy functions when $b$ is increased or decreased. Panel to the left shows the policy function when $b$ is reduced to 2 , and therefore increasing the range of discount up until $50 \%$. Next, panel to the right shrinks the range of discount by half as $b$ is assigned a value of 8 and the range of discount is bounded by $12.5 \%$. As expected skilled agents are the ones that benefit the 
more from this discount and therefore the convergence for high quality capital speeds up. However, unskilled agents do not benefit from the discount as much. Since the price is a nonlinear function of skill and convex for small values of $s$, low skilled agents barely are affected by changes in $b$. This makes evident when comparing the policy function for low skilled agents in figure 7. In both cases, lows skilled agents policy function has a fixed point near 0.15 and the maximum capital they can ever reach is near 0.75 .

Comparatively to the benchmark policy function in figure 4 figure 6 and figure 7 are much more alike than 5. This is because, even though all three parameters $\omega, b$ and $\bar{p}$ have an effect on agents decision of investing, $\omega$ has an effect on wages while $b$ and $\bar{p}$ only affect the price of investment. Under those circumstances, $\omega$ has a more direct effect on the distribution of wages since it strikes it via the channel of investment and the capacity of problem solving each agent has and consequently each agent wage. In addition, due to the fact that skills are fixed, $\omega$ becomes a determinant for unskilled people. Low levels of $\omega$ might set a poverty trap for low skilled agents. Moreover, increasing the level of $\omega$ allows to compensate unskilled with investment in high quality capital and move the economy to a less

\section{IV.2 Fitting the data}

In this section I try to analyze how the model fits the data. To do so I use the same panel taken from the World Bank open database. I merge these panel with the OECD open database in order to access the Programme for International Student Assessment (PISA) test results. The PISA test grading system is design in order that grades have a normal distribution with mean 500 and standard deviation 100. These tests will be proxies for skill levels at country level. Given that the average grade from a country comes from a normal distribution, I can assume that the distribution for average grades by country is also normal. Provided the distribution of skills, I can calculate the probability from each skill and test some of the model predictions against the real data. Nevertheless, under those circumstances I can only provide a qualitative comparison since the data I have access to is at a country level while the model is at a household level. In addition, the calibration of the model is done following the parameters presented in 1 and therefore the policy function is the one presented in figure 4. One of the main concerns this work is how the skill level affects the way agents invest in new capital. I interpret R\&D in the model as the investment each agent does on capital. Figure 8 shows the relation between skills and expenditure in $\mathrm{R} \& \mathrm{D}$. The $x$ axis measures 
Figure 8: Expenditure in R\&D as (\%) of wage.

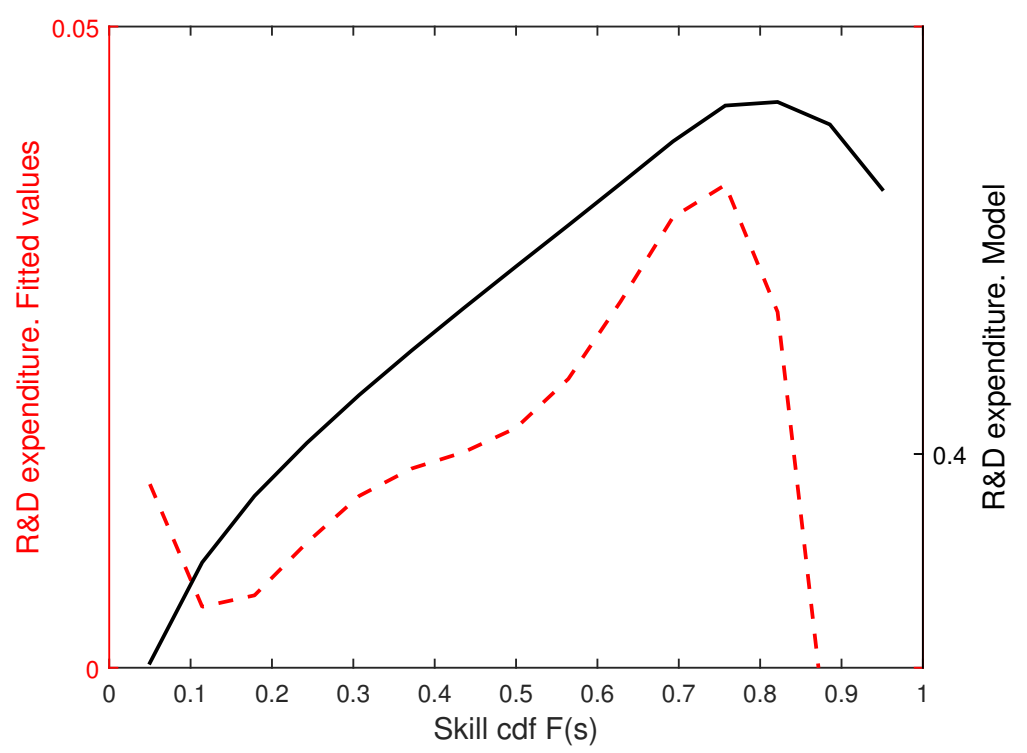

the probability of each skill level or $\operatorname{Pr}(S \leq s)$ and the $y$ axis has investment in $\mathrm{R} \& \mathrm{D}$ as a percentage of the GDP or wage given that case. Since data is not able to capture discounts on R\&D investment due to skill, I plot what the agent would have paid without discount. This means that in figure 8 plots $\frac{\bar{p} I}{w}$ even though agents real expenditure was $\frac{p(s) I}{w}$.

To compare the real data with the predicted function I use polynomial approximation methods in order to derive a function out from the data. The proxy I use for skills are results for mathematics from the PISA tests. Though the magnitudes in figure 8 does not match the tendency are very much alike. Low levels of skill limit the capacity of production and therefore the available resources to invest in R\&D. However, as the skill level grows production also grows and therefore the expenditure in $R \& D$ increases. Observe that both functions in figure 8 reach a maximum near the 75 percentile of skills. Two possible explanations arise for understanding this phenomena. First, highly skilled agents do not acquire the best technology but settle with a another less advance technology and compensate with their skills. This case, though, is highly dependent on how much agents can compensate the lack of technology with their skill. The value of $\omega$ determines this and figure 5 examined in more detail the different scenarios. The other possible explanation comes when highly skilled reach the best capital and then their expenditure in $R \& D$ is only to keep technology up to date.

The fact that the model matches the tendency as in figure 8 provides evidence in favor of 
Figure 9: Distribution of wages
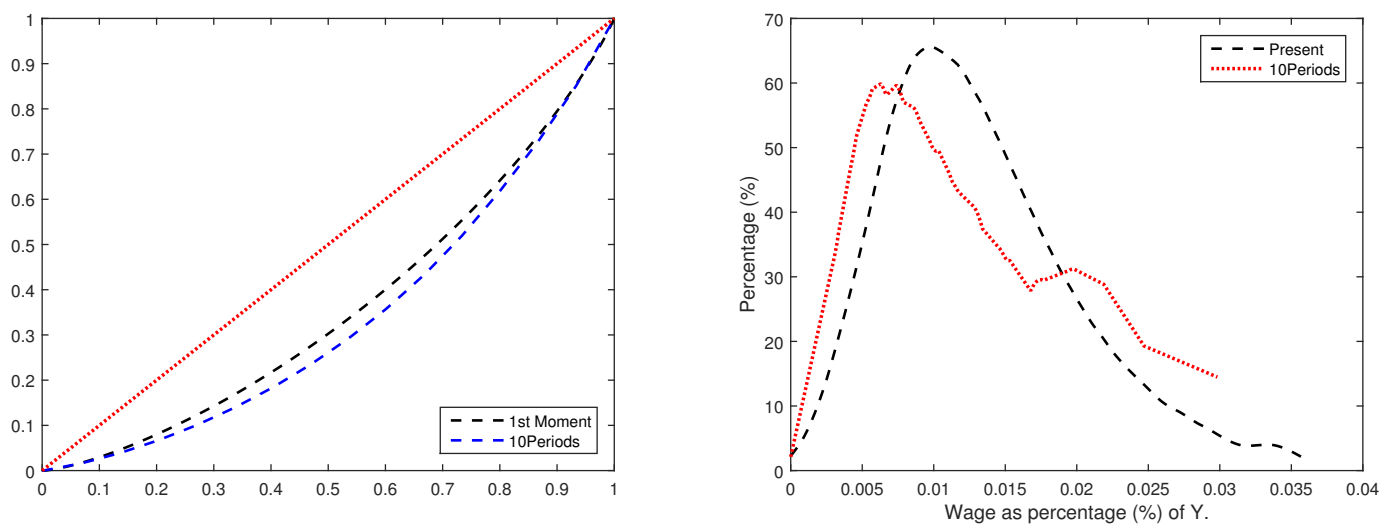

the dynamics I am arguing. In addition to that, the model predicts that wages will polarize with time. In figure 9 is presented the Lorenz curve and the distribution of wages. The dashed line represents initial state of the economy and the doted line the state of the economy after five periods of time. The Lorenz curves shows that during those five periods of time income inequality raised. Further, the curves match near the endpoints but they differ in the middle. This suggests that the raise in inequality comes from agents in the middle of the distribution. Panel to the right in figure 9 makes the effect even more clear. After five periods of time, though the support of the distribution shrunk the tails became heavier. Under those circumstances, seems that the middle class experienced a reduction in size but the low class benefit from it. These results are consistent with the report done by Alichi et al. (2016) in which they they show that the percentage of households with middle income has decreased while low and high income households have rise. These patterns are also consistent with the data presented in II.

\section{Conclusions}

This work develops a model to provide an alternative explanation for the rising wage inequality between skilled and unskilled individuals. Literature has shown that the source for this rising inequality has been a skilled biased technological change. However, there are several examples in history that questions the nature of skills. In this work I develop a theory that is consistent with both, the data and the anecdotal examples. Instead of assuming a complemen- 
tary relation between skills and technology in the process of production, I claim that skills reduce costs of learning new technologies. Therefore, skills act as a boost in the process of acquiring new technologies.

To support the hypothesis I develop a model in which agents solve problems and sell their solutions. To solve problems, agents use technology and their skill. As technology becomes obsolete, agents need to learn and master new technologies to keep themselves competitive. Skilled individuals receive discounts while investing as their learning costs are smaller. The model predicts two different sources of inequality. First, skills give agents an edge when solving problems which increases their wages. Next, skills expand the frontier of accessible technology as their costs are driven down. Finally, the model fits some macroeconomic trends in qualitative terms. Specifically, the model tracks the relation between skills and investing in R\&D. Also, the model is able to describe changes in the distribution of wages consistent with recent findings. Future work consists in calibrating the model using data at household level. 


\section{References}

Acemoglu, D. (1998). Why do new technologies complement skills? directed technical change and wage inequality*. The Quarterly Journal of Economics, 113(4), 1055.

Acemoglu, D., \& Autor, D. (2011). Chapter 12 - skills, tasks and technologies: Implications for employment and earnings*. In D. Card \& O. Ashenfelter (Eds.), (Vols. 4, Part B, p. 1043 - 1171). Elsevier.

Acemoglu, D., \& Restrepo, P. (2016). The race between machine and man: Implications of technology for growth, factor shares and employment (Working Paper No. 22252). National Bureau of Economic Research.

Alichi, A., Kantenga, K., \& Solé, J. A. (2016). Income polarization in the united states (Working Paper No. 16/121). International Monetary Fund.

Allen, J., \& de Grip, A. (2012). Does skill obsolescence increase the risk of employment loss? Applied Economics, 44(25), 3237-3245.

Autor, D. H., Katz, L. F., \& Krueger, A. B. (1998). Computing inequality: Have computers changed the labor market? The Quarterly Journal of Economics, 113(4), 1169-1213.

Beaudry, P., Doms, M., \& Lewis, E. (2006). Endogenous skill bias in technology adoption: City-level evidence from the it revolution (Working Paper No. 12521). National Bureau of Economic Research.

Beaudry, P., Green, D. A., \& Sand, B. M. (2009). The great reversal in the demand for skill and cognitive tasks. The Quarterly Journal of Economics, 124(2), 843-881.

Caicedo, S., Robert E. Lucas, J., \& Rossi-Hansberg, E. (2016). Learning, career paths, and the distribution of wages (Working Paper No. 22151). National Bureau of Economic Research.

Galor, O., \& Moav, O. (2000). Ability-biased technological transition, wage inequality, and economic growth. The Quarterly Journal of Economics, 115(2), 469-497.

Jovanovic, B., \& Nyarko, Y. (1996). Learning by doing and the choice of technology. Econometrica, 64(6), 1299-1310. 
Mokyr, J. (1990). The lever of riches: Technological creativity and economic progress. Oxford University Press.

Nelson, R. R., \& Phelps, E. S. (1966). Investment in humans, technological diffusion, and economic growth. The American Economic Review, 56(1/2), 69-75.

Weiss, M. (2008). Skill-biased technological change: Is there hope for the unskilled? Economics Letters, 100(3), 439-441. 